Article

\title{
Combination of Pre-Pulse and Constant Pumping Rate Hydraulic Fracturing for Weakening Hard Coal and Rock Mass
}

\author{
Qingying Cheng ${ }^{1}$, Bingxiang Huang ${ }^{2, *}$, Luying Shao ${ }^{2}$, Xinglong Zhao ${ }^{2}$, Shuliang Chen ${ }^{3}$, \\ Haoze $\mathrm{Li}^{2}{ }^{-10}$ and Changwei Wang ${ }^{2}$ \\ 1 Jiangsu Key Laboratory of Fire Safety in Urban Underground Space, China University of Mining and \\ Technology, Xuzhou 221116, China; chengqingying@cumt.edu.cn \\ 2 State Key Laboratory of Coal Resources and Safe Mining, China University of Mining and Technology, \\ Xuzhou 221116, China; shaoluying@cumt.edu.cn (L.S.); xinglongzhao@cumt.edu.cn (X.Z.); \\ lihaoze@cumt.edu.cn (H.L.); changweiwang@cumt.edu.cn (C.W.) \\ 3 School of Safety Engineering, China University of Mining and Technology, Xuzhou 221116, China; \\ chenshuliang@cumt.edu.cn \\ * Correspondence: huangbingxiang@cumt.edu.cn; Tel.: +86-1358-539-8762
}

Received: 20 August 2020; Accepted: 19 October 2020; Published: 22 October 2020

\begin{abstract}
The weakening of hard coal-rock mass is the core common problem that is involved in the top coal weakening in hard and thick coal seams, the hard roof control during the initial mining stage in the longwall mining face, and the hanging roof control in the gob of non-coal mine. Based on the characteristics of pulse hydraulic fracturing and constant pumping rate hydraulic fracturing, a weakening method for hard coal-rock mass by combining pre-pulse and constant pumping rate hydraulic fracturing is proposed. A complete set of equipment for the combined pulse and constant pumping rate hydraulic fracturing construction in the underground coal mine is developed. The pulse and constant pumping rate hydraulic fracturing technology and equipment were applied in the top coal weakening of the shallow buried thick coal seam. Compared with no weakening measures for top coal, the average block size of the top coal caving was reduced by $42 \%$ after top coal hydraulic fracturing. The recovery rate of the top coal caving mining face reached $85 \%$, and it increased by $18 \%$ after hydraulic fracturing.
\end{abstract}

Keywords: hard coal-rock mass; pulse hydraulic fracturing; constant pumping rate; fractures network; top coal weakening

\section{Introduction}

The weakening of hard coal-rock mass is the core common problem that involved in the top coal weakening in hard and thick coal seams, the control of the hard roof during the initial mining stage in the longwall mining face, and the control of the hanging roof in the gob of non-coal mine $[1,2]$. The traditional method of weakening coal-and-rock mass is explosive blasting [3,4]. However, a large number of toxic and harmful gases and dust will be produced after blasting. The explosive blasting is easy to induce or intensify rockburst. Besides, due to its potential safety hazard, it is not suitable for a high-gas coal mine. Meanwhile, the management of explosive blasting is complex. Safety and controllability are poor, and the cost is high [5-7]. Hydraulic fracturing is an effective technical way to weaken coal-rock masses. The action of high-pressure water artificially increases cracks in coal-rock mass and weaken the strength. The greater the number of hydraulic fractures and the greater the propagation range, the better the weakening effect on coal-rock mass [8-10]. Therefore, 
controlling the number and length of hydraulic fractures is the key to weakening coal-rock mass by hydraulic fracturing.

At present, the conventional hydraulic fracturing in coal mines uses a high-pressure pump with a constant pumping rate. During hydraulic fracturing, the fracture of the borehole wall is a static process. The initiation and propagation direction of the main hydraulic fractures are controlled by the three-dimensional in situ stress field, which is perpendicular to the direction of the minimum principal stress [11]. Finally, relatively few hydraulic fractures are formed in coal-rock mass (Figure 1). However, the high-pressure water that drives fracture propagation by conventional hydraulic fracturing with constant pumping rate is continuous, stable, and concentrated, which can ensure a long distance of fracture propagation. Therefore, the characteristic of conventional hydraulic fracture with a constant pumping rate is less and long.

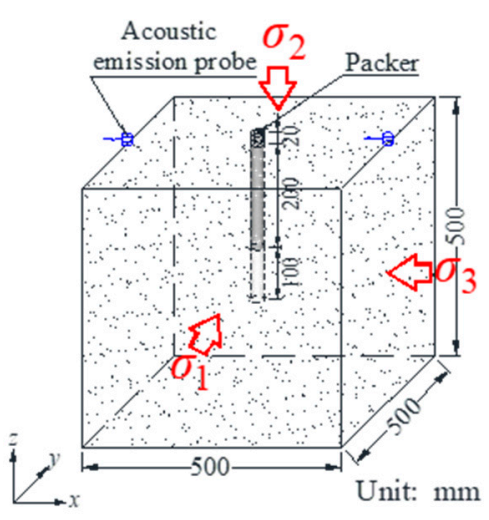

(a)

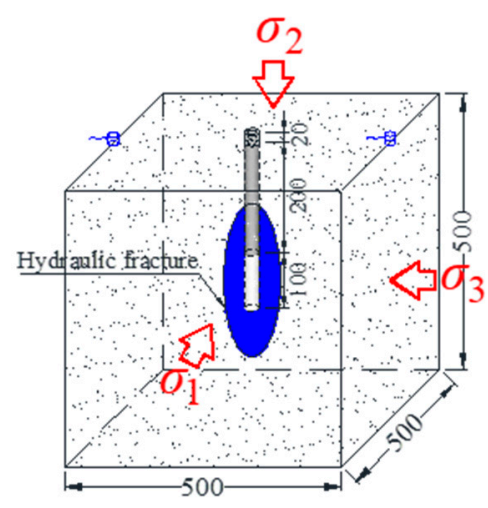

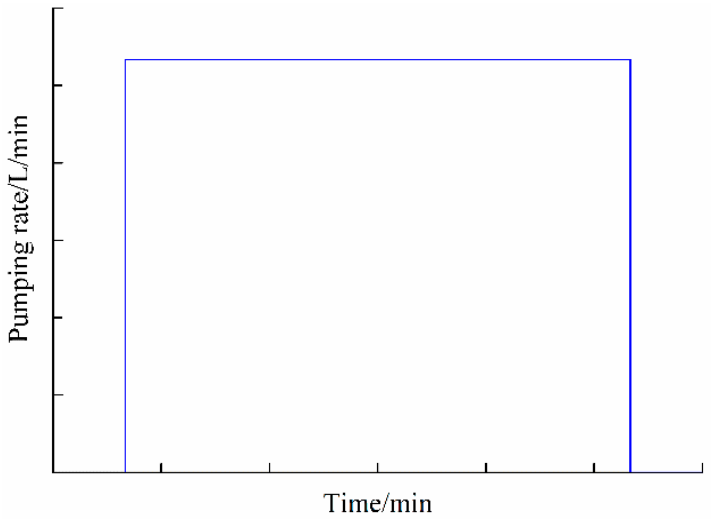

(b)

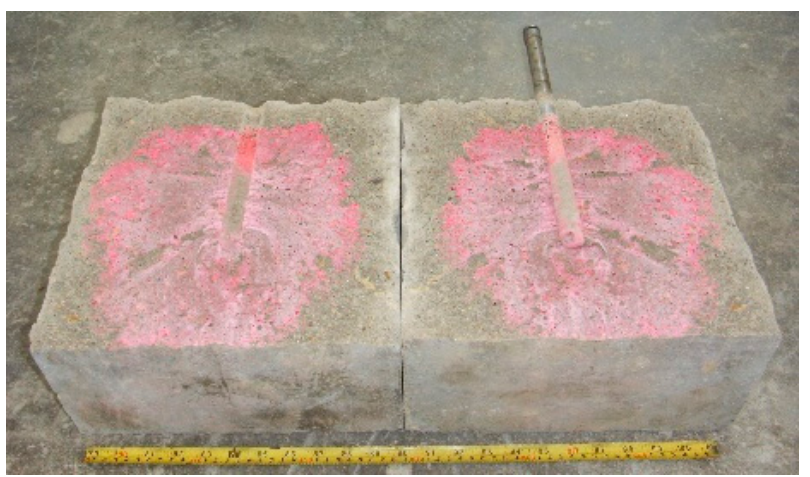

(c)

Figure 1. The conventional hydraulic fracturing performed by constant pumping rate: (a) cube test sample, (b) pumping process, and (c) hydraulic fracture morphology.

Pulsed hydraulic fracturing is one kind of hydraulic fracturing that a pulse pump is utilized to pump water into the coal-rock mass with a pulse pumping rate. During the pulse hydraulic fracturing process, the pumping rate is high-frequency periodic fluctuations in the form of pulse waves. The permeability enhancement effect of the coal seam can be improved by generating new fractures or expand the original fractures and pores in the coal seam [12-14]. On the one hand, the generated unsteady water pressure produces fatigue damage to coal-and-rock mass and reduces its strength [15]. Under the action of continuous cyclic load, the fracturing of the borehole wall is a dynamic process that can overcome the influence of in situ stress. The borehole wall ruptures in multiple directions, resulting in a relatively large number of hydraulic fractures (Figure 2). Meanwhile, under the periodic impact of pulsed water pressure, the original cracks inside the coal-rock body reopened and expanded to connect $[16,17]$. Finally, a relatively complex hydraulic fracture network is formed in coal-rock 
mass. On the other hand, the impact of pulse load on coal seam porosity is greater than that of static pressure load. There are two types that coal seam porosity is affected by pulse wave. One is the expansion of the original pore, and the other is the new pores formed by the erosion of mineral crystal embedded in the coal body [18]. Pulse pressure and frequency have a great impact on the effect of pulse hydraulic fracturing. The effect of pulse hydraulic fracturing can be enhanced by optimizing the combination of pressure and frequency [19-22]. Compared with conventional hydraulic fracturing and deep-hole blasting, the gas drainage performance of pulse hydraulic fracturing technology is superior. The drainage concentration is relatively high, and the gas attenuation is small [23]. However, since the pump rate of the pulse hydraulic fracturing fluctuates periodically, the effect of the pulse pressure used to drive the expansion of the pulse hydraulic fractures is not continuous. Besides, the pumping rate of the pulse pump currently used in coal mines is relatively low. Compared to conventional hydraulic fracturing with a large constant-pumping rate, the extension range of the pulse hydraulic fractures is small. Therefore, the characteristic of the pulse hydraulic fracture is dense and short.

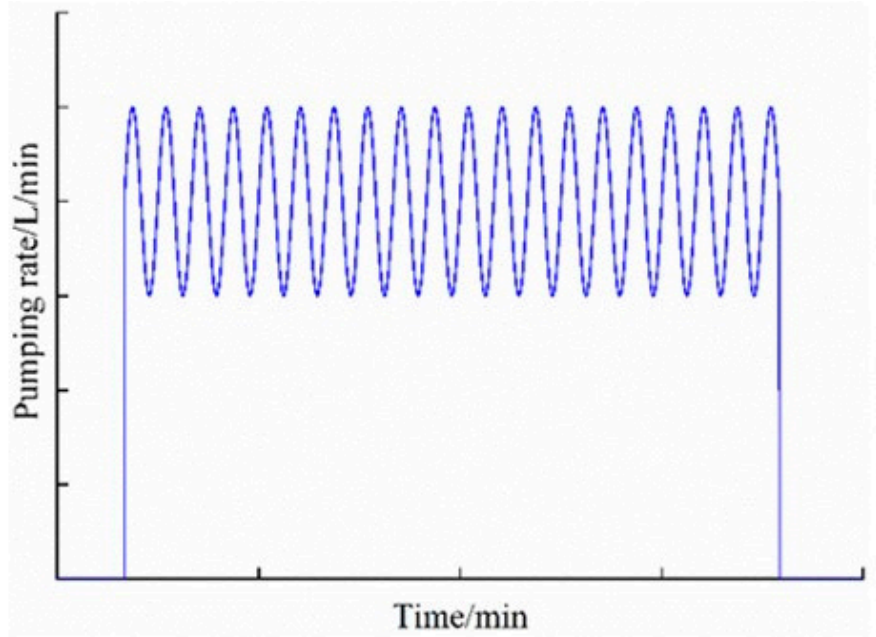

(a)
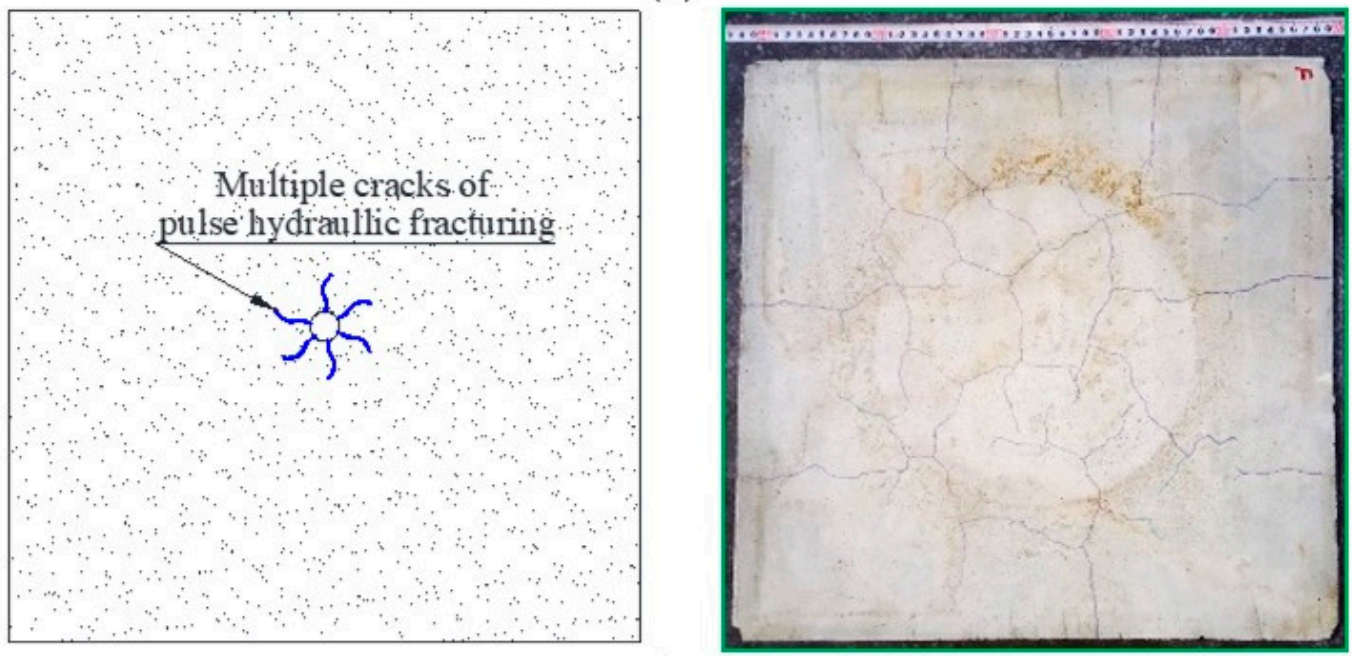

(b)

Figure 2. The hydraulic fracturing performed by pulse pumping rate: (a) pumping process and (b) hydraulic fracture morphology.

Different engineering backgrounds have different requirements for the weakening degree of coal-rock mass. Therefore, in actual construction, it is necessary to determine the optimal hydraulic fracturing and weakening process of coal-rock mass according to the project requirements. In the weakening project of the hard roof in a coal mine, it is only necessary to generate artificial hydraulic 
fractures in the roof rock mass. The integrity of the hard roof is destroyed, and it can cave in time under the action of mine pressure. There is no requirement for the caving block size of the roof $[24,25]$. Therefore, the number of required hydraulic cracks is relatively small. In general, the conventional hydraulic fracturing with constant pumping rate can meet the requirements. However, for the weakening of top coal in the hard and thick coal seam, artificial cracks need to be produced in the top coal to induce the top coal caving timely. Besides, a large number and extension range of artificial cracks is required to reduce the caving block size of the top coal. The hydraulic cracks network fully cuts the coal body, reduces the caving block size of top coal, and improves the top coal recovery ratio. Therefore, the weakening of hard and thick top coal requires a high weakening degree of the hydraulic fracturing of coal-rock mass.

In this paper, based on the characteristics of pulse hydraulic fracturing and constant pumping rate hydraulic fracturing, a weakening method for hard coal-and-rock mass by combining pre-pulse and constant pumping rate hydraulic fracturing is proposed. Firstly, pulse hydraulic fracturing is used to create an artificial fracture network in the coal-rock mass, which is not controlled by in situ stress. The original cracks in the coal-rock mass can be fully activated. Secondly, constant pumping rate hydraulic fracturing is used to further expand the fracture network system formed by pulse hydraulic fracturing. The coal-rock mass is fully crushed and weakened. The weakening effect of coal-rock mass can be improved.

More research has been conducted on conventional hydraulic fracturing with a constant pumping rate. At present, a large number of engineering applications have been carried out in coal mines, including hard roof control, stress transfer for control dynamic deformation of tunnels, and permeability enhancement in the low permeability coal seam [26-30]. Pulse hydraulic fracturing is rarely used in coal mines. Some field test of pulse hydraulic fracturing has been performed to enhance the permeability of coal seams. The fatigue effect was used to increase secondary cracks under a lower pulse pressure, thereby improving the effect of increasing the permeability of coal seams [12-14]. There is no research on the weakening method and process for hard coal-and-rock mass by combining pre-pulse and constant pumping rate hydraulic fracturing.

\section{Theoretical Analysis of Hard Coal-and-Rock Mass Weakening by Pulse Hydraulic Fracturing}

In the process of pulse hydraulic fracturing, the pulse water pressure propagates in the form of a sine wave. When the pulse pressure wave is transmitted to the interface between the water and the fracture tip of the coal-rock body, a pulse incident wave and a pulse reflected wave is generated. The reflection and superposition of the pulse pressure wave cause the amplitude of the pulse pressure wave increase, as well as the peak value of the pulse pressure wave. Moreover, due to the friction resistance, the water pressure increase phenomenon will also occur at the tip of the fracture. In addition, high-frequency pulse water pressure continuously impacts coal-and-rock mass, which will cause fatigue damage to coal-and-rock mass. A large number of cracks in multiple directions are generated inside the coal-rock mass. It does not only increase the number of cracks but also break through the constraints of joints, bedding, and stress fields on uniform hydraulic fracturing. Finally, a complex and uniform hydraulic fracture network is formed in coal-and-rock mass.

\subsection{Superposition Effect of Pulse Incident Wave and Reflected Wave}

The pulse pressure after the superposition of incident pulse wave and reflected wave is shown in Formula (1) [31].

$$
\sigma(x, t)=\sigma_{1}(x, t)+\sigma_{R}(x, t)=\sigma_{0} \sin \left[\omega\left(t-\frac{x}{c_{p}}\right)\right]-V \sigma_{0} \sin \left[\omega\left(t-\frac{2 L-x}{c_{p}}\right)\right], t>\frac{2 L-x}{c_{p}}
$$


where $\sigma_{0}$ is the average threshold value of uniaxial compressive strength of a large number of micro elements, $L$ is the fracture length, $\omega$ is the angular velocity of transmission shaft, $c_{p}$ is the wave velocity, and $V$ is the reflection coefficient.

In the coal-and-rock mass, the stress increases in some places and is eliminated in other places. The smaller pulse pressure wave produces larger pulse pressure locally, which intensifies the damage of coal-and-rock mass.

\subsection{Friction Resistance Effect}

Due to the friction resistance, the pulse pressure increases at the fracture tip. The increase of pulse pressure is shown in Equation (2) [32].

$$
\Delta H=-\frac{C}{g} \Delta V \pm \frac{F_{f}}{\rho g A}
$$

where $\rho$ is the water density, $A$ is the fracture cross-sectional area, $C$ is the pressure wave velocity, $V_{0}$ is the initial velocity, $\Delta V$ is the velocity change, $\Delta H$ is the water head change, and $F_{f}$ is the friction resistance.

The above formula shows that there is an additional term $\frac{F_{f}}{\rho g A}$ for the variation of pressure amplitude caused by viscous friction resistance, and its magnitude is directly proportional to the friction resistance coefficient, and the symbol is related to the flow direction. When the pulsed flow reaches the fracture tip and reflects and reverses the flow, it is the same sign as $\frac{C}{g} \Delta V$, which leads to the increase of the pulse water pressure at the fracture tip.

\subsection{Fatigue Damage Effect}

The propagation of pulse pressure waves in coal-and-rock mass will excite particle vibration along a random direction. The long-term vibration changes the connection between particles and weakens the strength of the connection in several ways. The weakening process makes the coal and rock undergo fatigue damage, and, finally, plastic yield occurs. The damage quantity can be calculated by means of elastoplastic continuum damage mechanics [15,33].

$$
D=1-\frac{\widetilde{E}}{E_{0}} \frac{\varepsilon_{0}-\widetilde{\varepsilon}}{\varepsilon_{0}}
$$

where $\varepsilon_{0}$ and $\widetilde{\varepsilon}$ are the strains before and after loading, and $E$ and $\widetilde{E}$ are the elastic modulus before and after loading, respectively.

Therefore, after pulse hydraulic fracturing for a period of time, the strength of coal-and-rock mass decreases periodically, as follows:

$$
\widetilde{\sigma}=\sigma_{0}\left(\frac{\widetilde{E}}{E_{0}} \frac{\varepsilon_{0}-\widetilde{\varepsilon}}{\varepsilon_{0}}\right)^{\frac{2 \pi t}{\omega}}
$$

\section{Weakening Methods by Combining Pre-Pulse and Constant Pumping Rate Hydraulic Fracturing}

\subsection{Weakening Principle}

The weakening principle of combining pre-pulse and constant pumping rate hydraulic fracturing is shown in Figure 3. Firstly, a pulse pump is used to inject water with pulse pumping rate into the borehole of the coal-rock mass. Under the action of relatively low pulse pressure, high-frequency pulse pressure waves can generate short and dense new cracks in different directions. Besides, the natural cracks in coal-rock bodies can be activated. The natural cracks reopen and expand, resulting in a complex short and dense uniform crack network around the hydraulic fracturing borehole. 


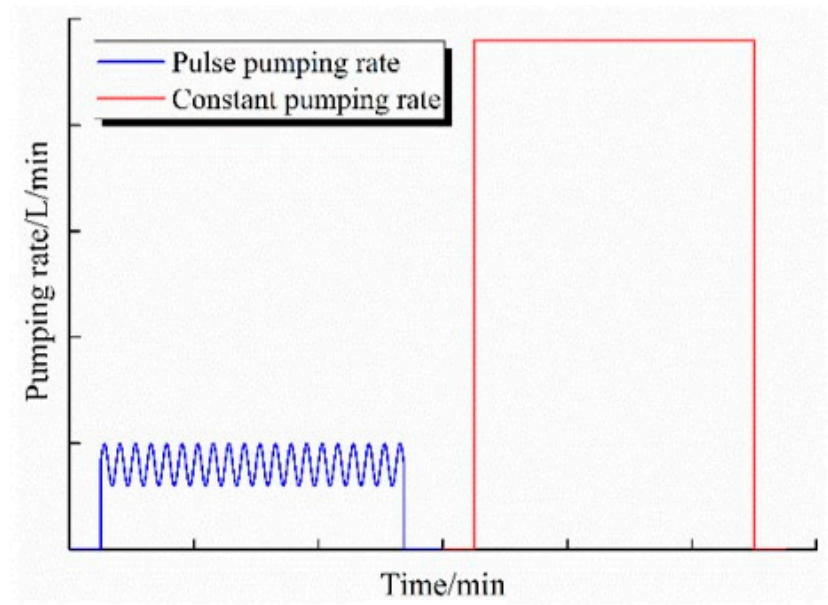

(a)

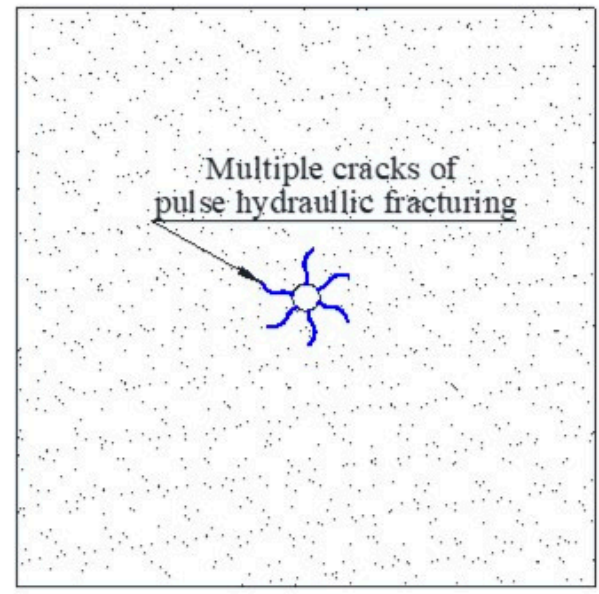

(b)

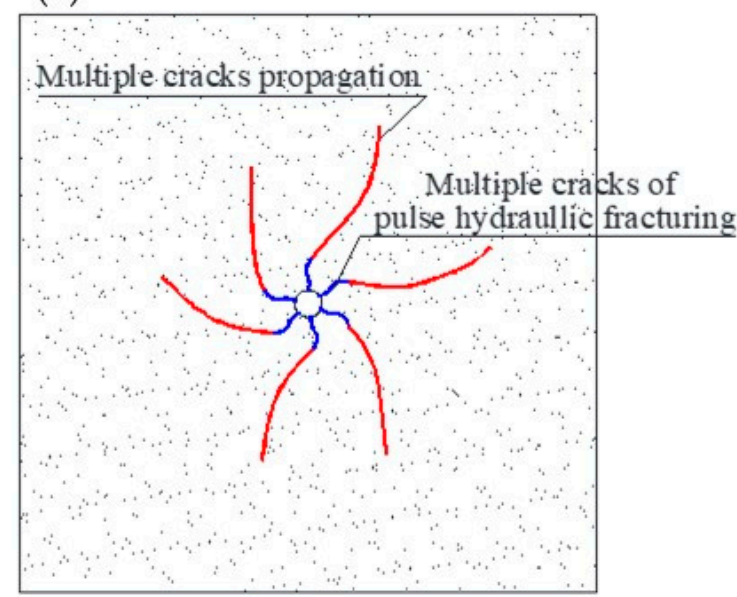

(c)

Figure 3. Schematic diagram of combining pre-pulse and constant pumping rate hydraulic fracturing: (a) pumping process, (b) pre-hydraulic fracturing with pulse pumping rate, and (c) hydraulic fracturing with constant pumping rate.

Next, a high-pressure pump is used to inject high-pressure water with constant pumping rate into the hydraulic fracturing borehole. On the basis of the complex short and dense fracture network formed by pulse fracturing, taking advantage of the conventional hydraulic fracturing characteristics of high pressure, large pumping rate, and large fracture extension range, the fracture network continues to propagation to form a large number and a wider range of hydraulic fractures, which can expand the scope of a single-hole hydraulic fracturing to weaken coal-rock bodies, and improve the utilization rate of hydraulic fracturing drilling hole (Figure 3).

In short, this technology fully takes into account the characteristics of pulsed hydraulic fracturing and conventional hydraulic fracturing, promote strengths and avoid shortcomings. The macro and meso structure of the coal-rock mass is pre-destructed. The overall mechanical properties of the coal-rock mass are fully weakened. Besides, the permeability of the coal-rock mass improved, so that the coal-rock mass can fully absorb water and moisten, and the coal-rock mass is further softened.

\subsection{Technology Process}

The core of the weakening methods by combining pre-pulse and constant pumping rate hydraulic fracturing is to create a fracture network by pulse hydraulic fracturing. After that, expand the fracture network by constant pumping rate hydraulic fracturing. Therefore, the weakening methods by combining pre-pulse and constant pumping rate hydraulic fracturing is sequential rather than random. 
The technology process of combining pre-pulse and constant pumping rate hydraulic fracturing is shown in Figure 4. The high-pressure hose output from the pulse pump and the high-pressure pump is connected by a three-way valve. The shut-off valve I is installed in the pipeline between the pulse pump and the three-way valve, and the shut-off valve II is installed in the pipeline between the high-pressure pump and the three-way valve. The other end of the three-way valve is connected to the high-pressure sealing mounting rod through a high-pressure hose. The high-pressure hose is connected to the high-pressure seal mounting rod through a conversion joint, the high-pressure seal mounting rod is directly connected to the packer, and the sealing pressure of the packer is applied by a hand pump. When hydraulic fracturing starts, open the shut-off valve I and close the shut-off valve II, then turn on the pulse pump to perform pulse hydraulic fracturing to produce fractures network in the coal-rock body. After the pulse hydraulic fracturing continues for a period of time, turn off the pulse pump, close the shut-off valve I and open the shut-off valve II, turn on the high-pressure pump to further extend the pulse hydraulic fractures by large constant pumping rate injection. When a large area of water flows out around the hydraulic fracturing borehole, turn off the high-pressure pump and open the pressure relief valve on the pipeline, the test is completed. Remove and recover the pipeline and proceed to the next borehole hydraulic fracturing construction.

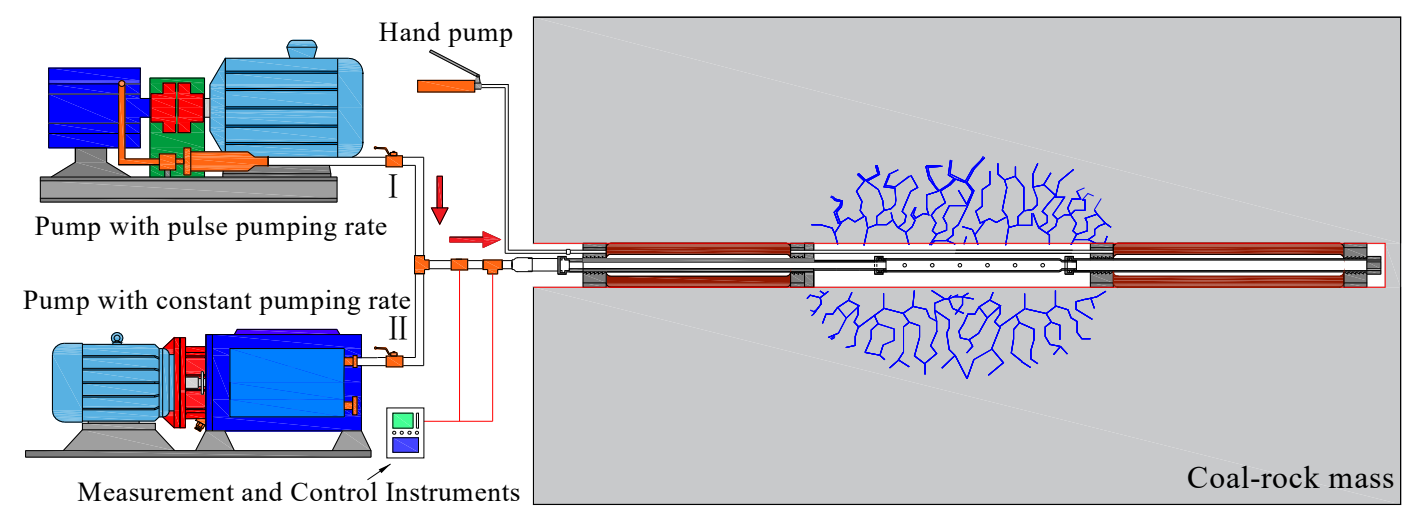

(a)

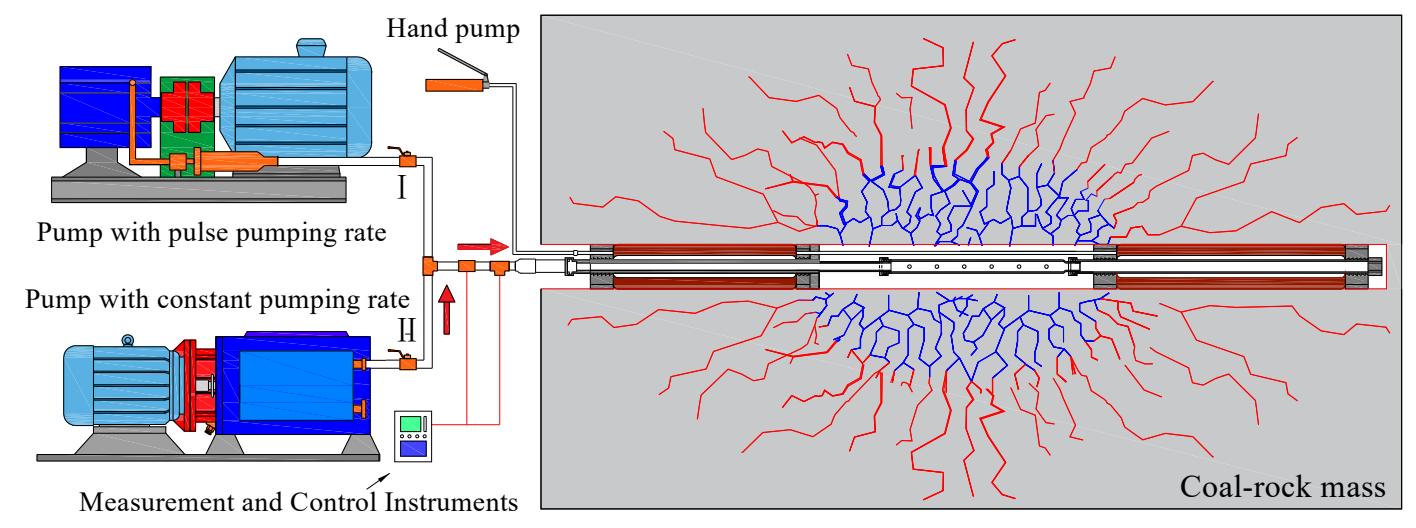

(b)

Figure 4. Technology process of combining pre-pulse and constant pumping rate hydraulic fracturing: (a) pulse hydraulic fracturing and (b) conventional hydraulic fracturing with constant pumping rate.

\section{Field Test Conditions}

Based on the weakening principle of the technology, the field test of the top coal weakening at 4307 fully mechanized caving face was carried out, which is located at Maohua Bailu Coal Industry, Pinglu District, Shuozhou City, Shanxi Province (Figure 5). 


\subsection{Geological Conditions}

The No. $4^{-1}$ coal seam is mined at the 4307 working face of Bailu Coal Mine, with a coal seam burial depth of $153-178 \mathrm{~m}$. The coal seam thickness is $5.7-8.3 \mathrm{~m}$, with an average of $7.5 \mathrm{~m}$. The inclination angle is $0^{\circ}-5^{\circ}$, generally about $2^{\circ}$. The coal seam is dominated by dark coal, with mirror coal and bright coal, bitumen gloss, large specific gravity, and hard quality (Table 1). The absolute gas emission is $0.55 \mathrm{~m}^{3} / \mathrm{min}$, and the relative gas emission is $1.13 \mathrm{~m}^{3} / \mathrm{t}$.

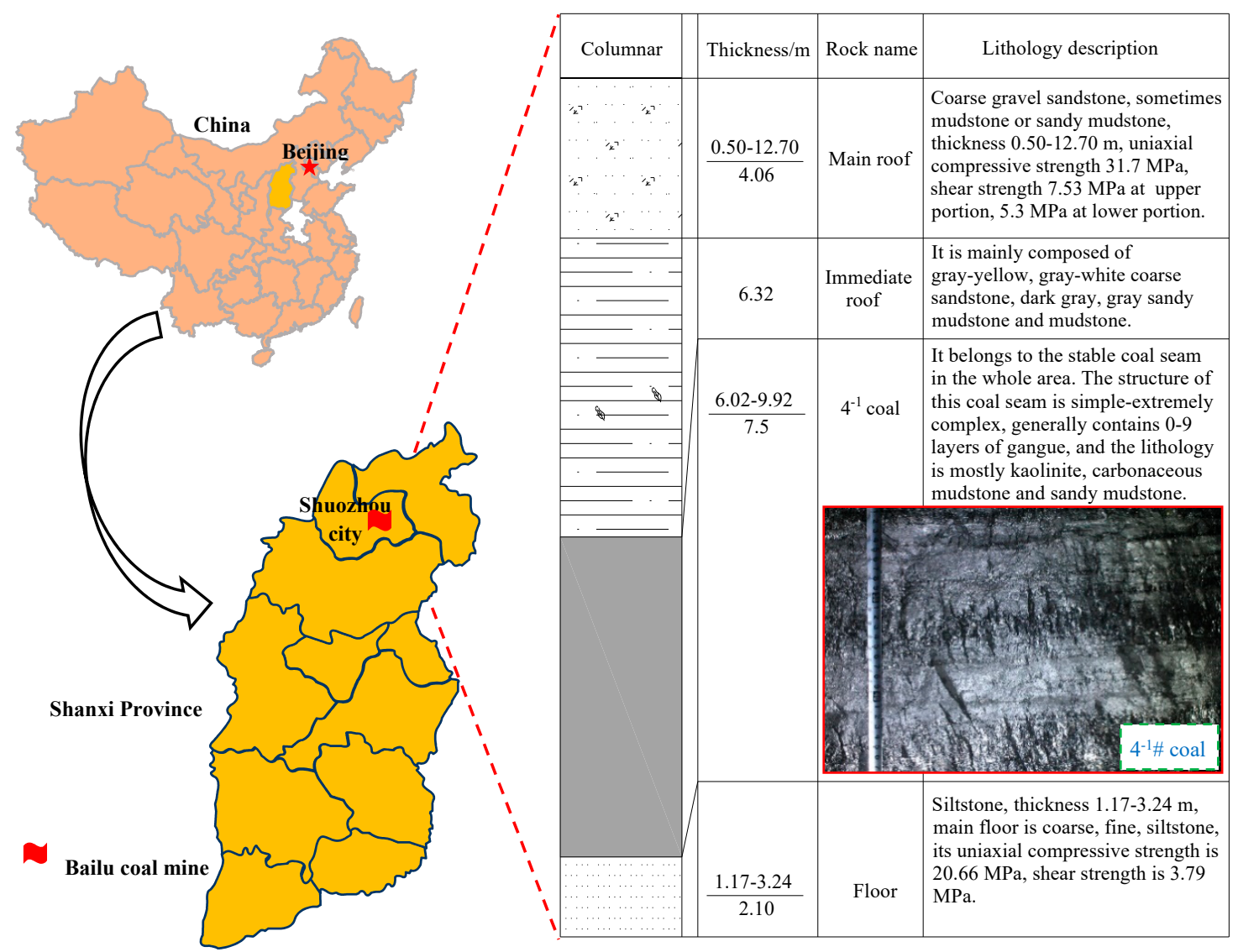

Figure 5. Geological map of coal seam in Bailu Coal Mine.

Table 1. The physical and mechanical parameters of coal-rock.

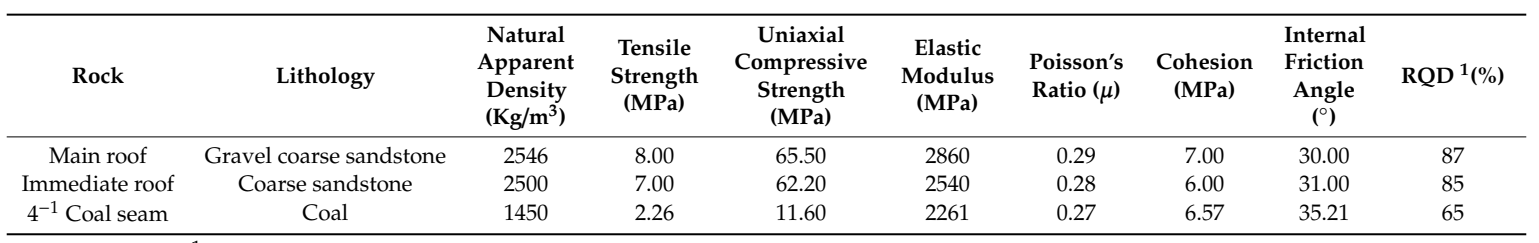

1. Rock Quality Designation (RQD) is a measure of quality of rock core taken from a borehole.

\subsection{Technical Conditions}

The length of the 4307 working face is $220 \mathrm{~m}$, and the continuous advancement length is $1730 \mathrm{~m}$. The head entry, tail entry, and opening cut are all excavated along the coal seam floor. The roof support method is "rock bolt + anchor cable + reinforced belt". The roadway section is rectangular, with a width of $4.6 \mathrm{~m}$ and a height of $3.2 \mathrm{~m}$. Long-wall comprehensive mechanized top coal caving mining is adopted, with a coal cutting depth of $0.6 \mathrm{~m}$, mechanical mining height of $3.2 \mathrm{~m}$, and top coal caving height of $4.3 \mathrm{~m}$. Single-wheel interval coal discharging method is adopted, and the coal discharging step distance is $0.6 \mathrm{~m}$. The working face has been advanced $150 \mathrm{~m}$ before the field test of the top coal weakening carrying out. 


\subsection{Analysis of the Existing Problems}

The coal seam of the 4307 working face is medium in hardness and strong in integrity. There are no obvious joint cracks in the coal seam. The bedding is not developed, and there is no visible opening. Due to the shallow coal seam depth, the mine pressure is not strong, which cannot effectively and fully rupture the top coal in time. It results in a large caving block of top coal and affects the top coal recovery rate (Figure 6).

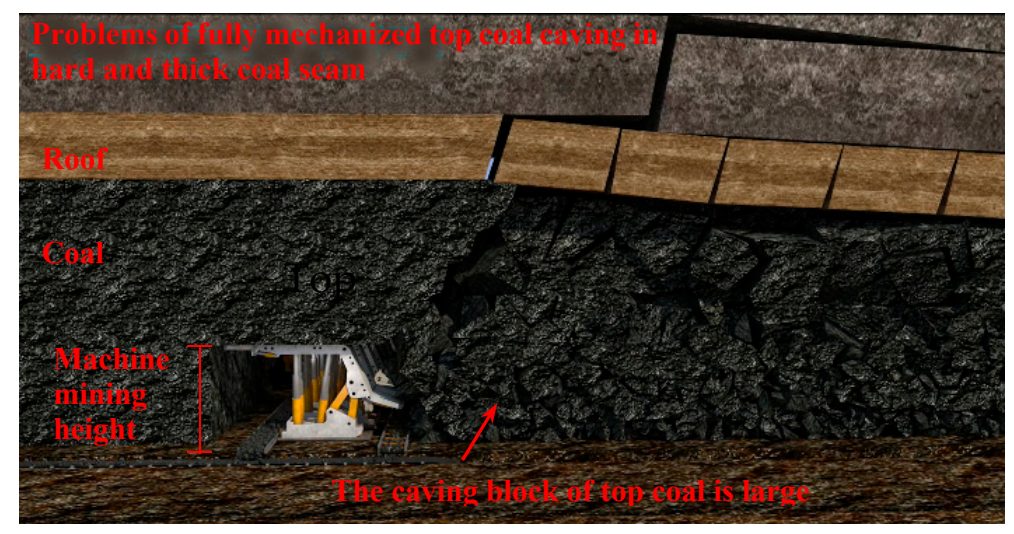

Figure 6. Top coal caving schematic diagram of fully mechanized top coal caving in hard and thick coal seam.

\section{Field Test Program of Top Coal Hydraulic Fracturing}

\subsection{Layout of the Hydraulic Fracturing Drillholes}

Two rows of hydraulic fracturing boreholes are separately drilled along the tilt direction of the coal seam at the head entry and tail entry of the 4307 working face. The orifice location is $1.5 \mathrm{~m}$ away from the roadway floor, and the borehole bottom position is $1 \mathrm{~m}$ away from the coal seam roof. The horizontal projection length of the borehole is $105 \mathrm{~m}$. The borehole diameter is $75 \mathrm{~mm}$, and the space between adjacent boreholes is $10 \mathrm{~m}$ (Figure 7). The boreholes of the two roadways are staggered. In order to avoid the impact of geological structures on the top coal fracturing effect, the layout of the boreholes should be based on geological data to keep away from the faults and other geological structures as far as possible.

\subsection{Layout of the Hydraulic Fracturing Equipment}

At present, the high-pressure pumps used in the market are displacement pumps, that is, the pumping rate is a control signal, while the water pressure is a feedback signal. The water pressure is related to the stress field, the mechanical strength of coal-and-rock mass, and fracturing technology. The rated pressure of the hydraulic fracturing pump must be high enough to ensure that the coal-and-rock mass can be fractured.

The hydraulic fracturing pump station, monitoring system, and control system are arranged at the transportation roadway, which is $100 \mathrm{~m}$ ahead of the 4307 working face (Figure 8). The rated pressure of the pulse hydraulic fracturing pump is $20 \mathrm{MPa}$, the pumping rate is $110 \mathrm{~L} / \mathrm{min}$, and the pulse frequency is $18 \mathrm{HZ}$. The rated pressure of the high-pressure hydraulic fracturing pump is $70 \mathrm{MPa}$, with a constant pumping rate of $200 \mathrm{~L} / \mathrm{min}$. The special rubber packer is adopted to seal the hydraulic fracturing borehole. According to the depth of hydraulic fracturing borehole, multiple high-pressure sealing installation rods are used to connect with the packer to achieve deep borehole sealing. 


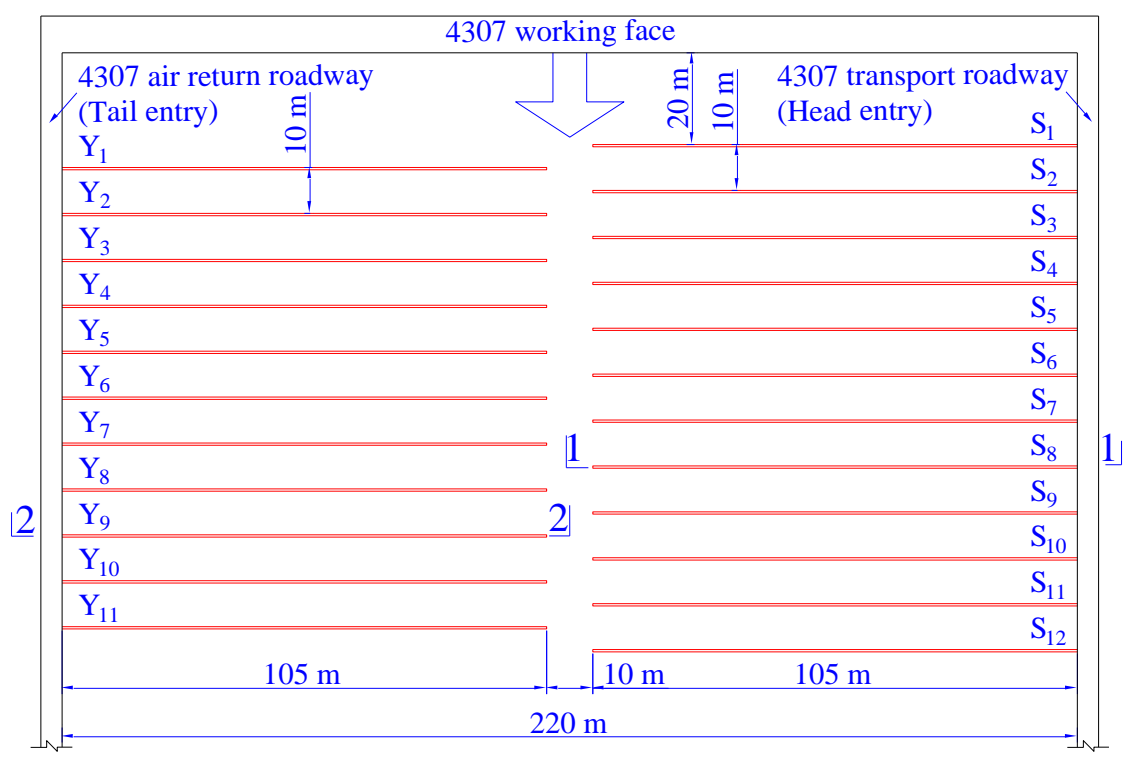

(a)

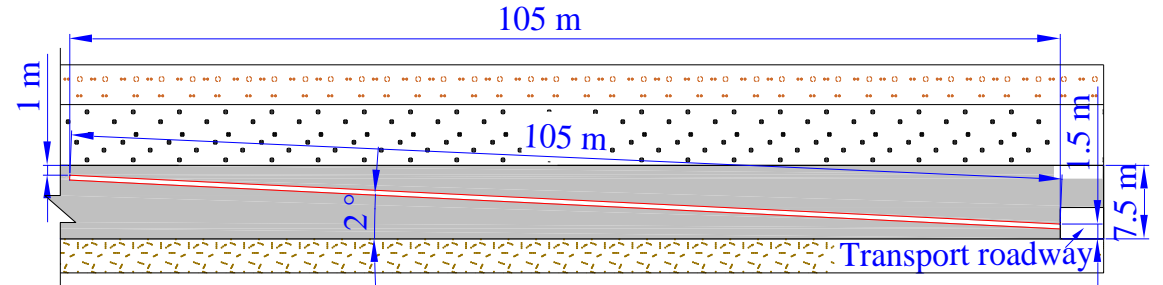

(b)

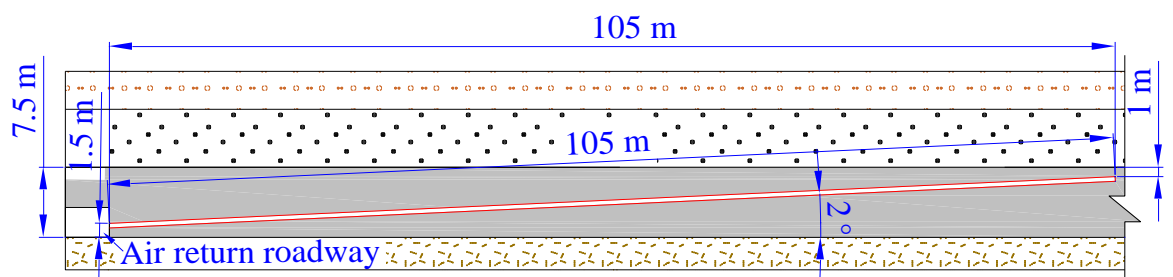

(c)

Figure 7. The layout of hydraulic fracturing boreholes: (a) plan view, (b) borehole at transport roadway (1-1 sectional view), and (c) borehole at air return roadway (2-2 sectional view). 


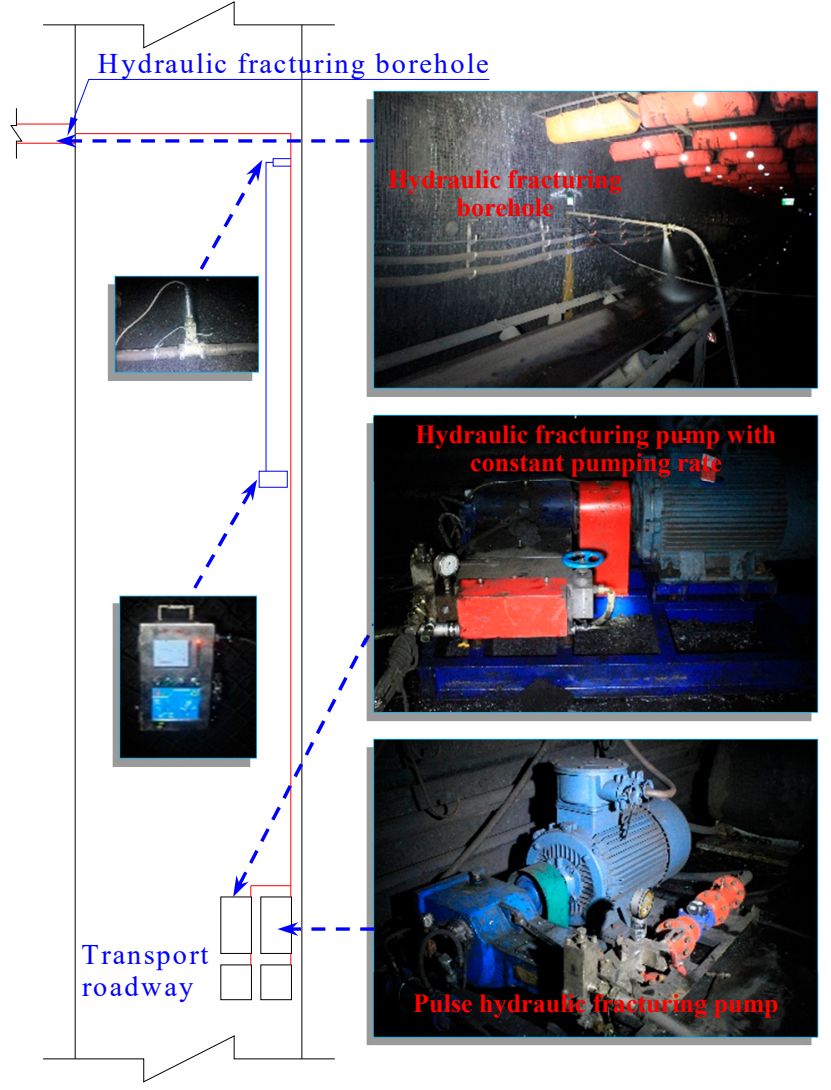

Figure 8. Layout of the hydraulic fracturing equipment.

\section{Field Test Process and Analysis of Top Coal Hydraulic Fracturing}

Since October 2017, a total of 203 hydraulic fracturing boreholes have been performed in the transportation and air return roadway of the 4307 working face. A hydraulic fracturing measurement and control instrument is used to real-time monitor and collect the construction water-pressure data during hydraulic fracturing (Figure 8). The data collection frequency is 1 time/second.

The water pressure is between 2 and $7 \mathrm{MPa}$ during pulse hydraulic fracturing and is between 8 and $20 \mathrm{MPa}$ during constant pumping rate hydraulic fracturing in the coal seam of Bailu Coal Mine. The water pressure during constant pumping rate hydraulic fracturing is greater than that of pulse hydraulic fracturing. During pulse hydraulic fracturing, there is at least one adjacent borehole where water flows out at the two sides of the hydraulic fracturing borehole, which indicated that the fractures propagation range is at least $10 \mathrm{~m}$. During the second stage of hydraulic fracturing with constant pumping rate, as the fracturing time increases, there may be four boreholes where water flows out at the two sides of the hydraulic fracturing borehole, which indicated that the fractures extension and connection range reach $40 \mathrm{~m}$.

Two typical hydraulic fracturing tests that combined pulse and constant pumping rate are shown in Figure 9. $\mathrm{S}_{18}$ hydraulic fracturing borehole is drilled with a borehole depth of $105 \mathrm{~m}$ and a sealing depth of $30 \mathrm{~m}$ at the transportation roadway. Firstly, the pulse pump is turned on for coal seam pulse hydraulic fracturing. The pulse hydraulic fracturing lasts for $40 \mathrm{~min}$ and $4.4 \mathrm{~m}^{3}$ water is injected into the borehole. During the pulse hydraulic fracturing process, the pulse water pressure fluctuates in the form of a sine wave in the range of 2-6 MPa. The pulse water continuously impacts and crush the coal body, and then a dense network of pulsed hydraulic fractures is formed in the coal seam. After the pulse hydraulic fracturing is completed, the pulse pump is turned off, and the high-pressure pump with a large constant pumping rate is turned on to start the second stage of hydraulic fracturing. The second stage of hydraulic fracturing with constant pumping rate lasts for $8 \mathrm{~min}$ and $1.6 \mathrm{~m}^{3}$ water 
is injected into the borehole. During this stage, the water pressure is between 8 and $17 \mathrm{MPa}$. Under the guidance of the pulse hydraulic fractures, the hydraulic fracturing with a large constant pumping rate further extends the pulse hydraulic fractures, and, eventually, a large-scale dense hydraulic fractures network is formed in the coal seam.

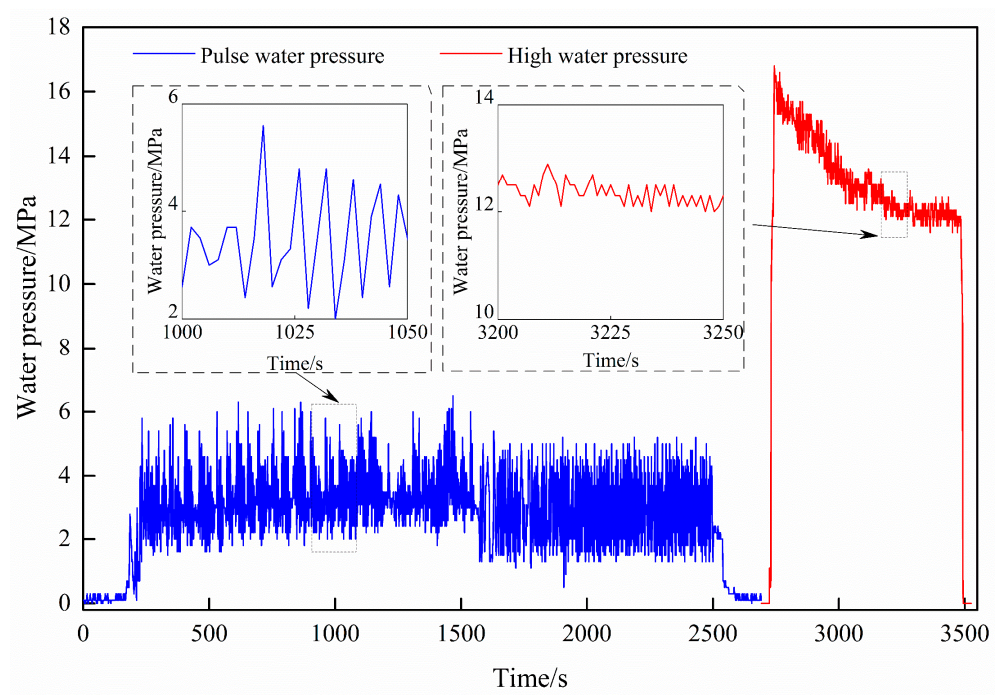

(a)

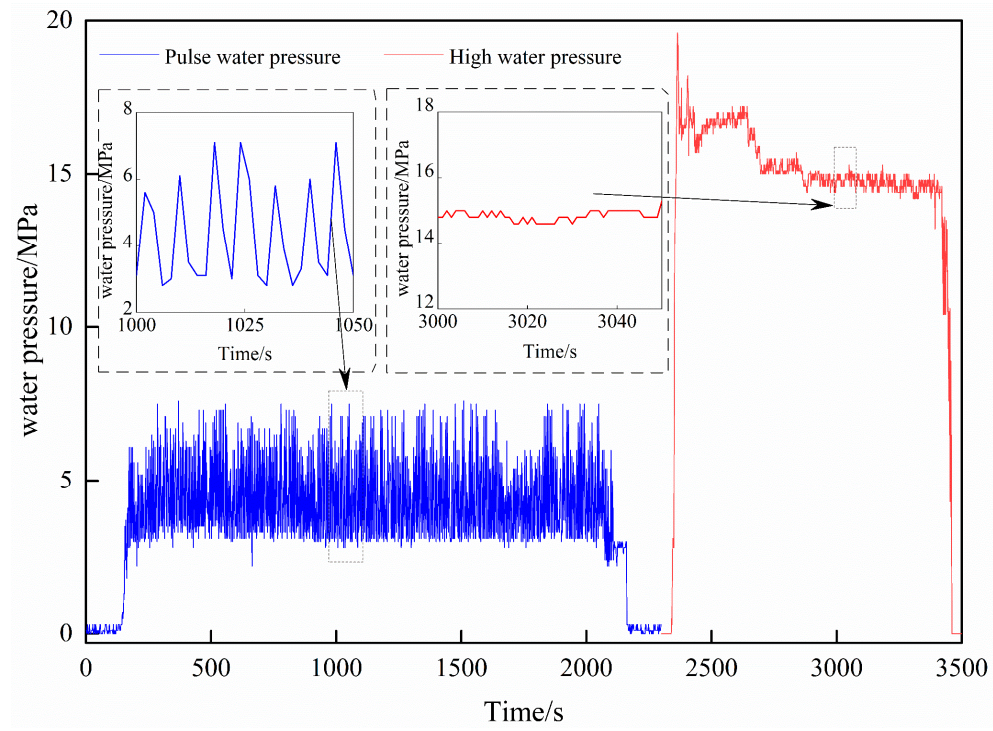

(b)

Figure 9. Water pressure during hydraulic fracturing: (a) $S_{18}$ borehole and (b) $S_{19}$ borehole.

During the hydraulic fracturing of the $\mathrm{S}_{18}$ borehole, the phenomena of water flow out from the adjacent boreholes and water seepage on the surrounding coal wall are observed (Figure 10). Water flows out from the $\mathrm{S}_{17}$ borehole, a large area of water seepage on the coal wall and roof between the $S_{17}$ borehole and the $S_{18}$ borehole. These phenomena indicate that a large scale of hydraulic fractures has been connected. The coal wall between $S_{18}$ borehole and $S_{19}$ borehole is partially wet. 


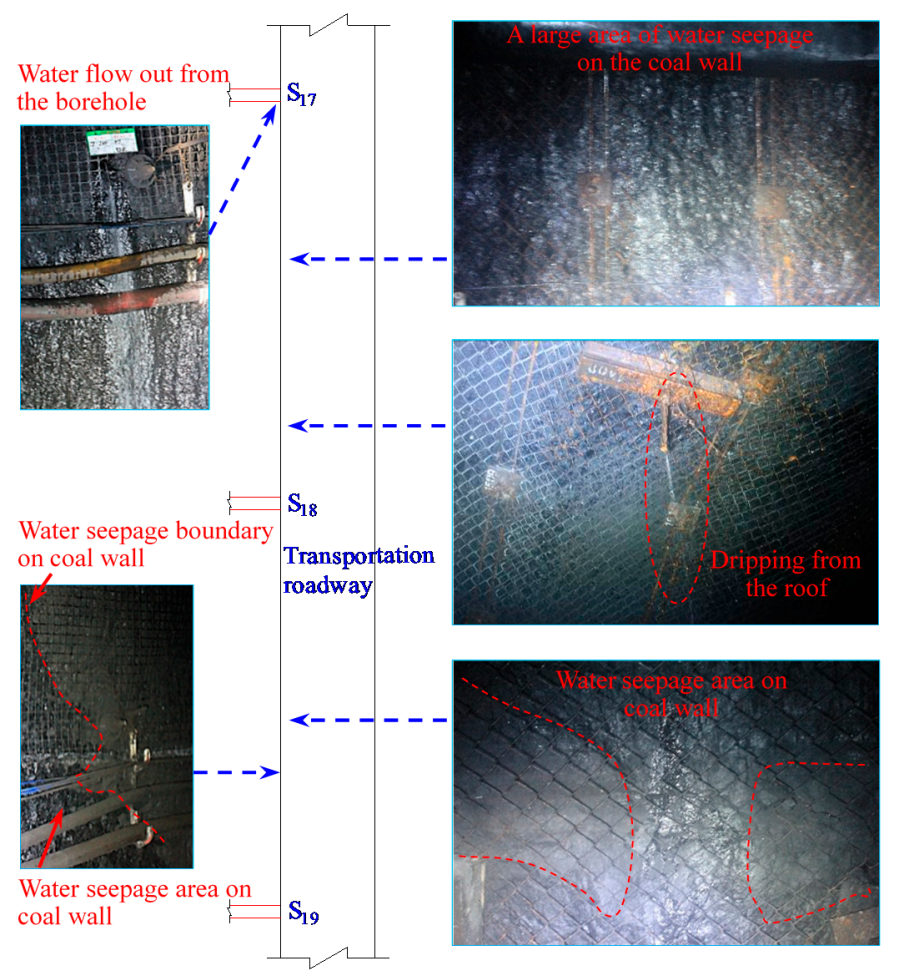

Figure 10. Water-seepage phenomenon during hydraulic fracturing of $S_{18}$.

$\mathrm{S}_{19}$ hydraulic fracturing borehole is drilled with a borehole depth of $105 \mathrm{~m}$ and a sealing depth of $60 \mathrm{~m}$ at the transportation roadway. The first stage is pulse hydraulic fracturing, which lasts for $36 \mathrm{~min}$. During this stage, $4 \mathrm{~m}^{3}$ water is injected into the borehole, and the pulse water pressure fluctuates within the range of 3-7 MPa. The second stage is hydraulic fracturing with large constant pumping rate which lasts for $20 \mathrm{~min}$. During this stage, $4 \mathrm{~m}^{3}$ water is injected into the borehole, and the water pressure is between 15 and $20 \mathrm{MPa}$.

During the pulse hydraulic fracturing of the $S_{19}$ borehole, a large amount of water flows out from the $S_{17}$ and $S_{18}$ borehole. Water also flows out from the anchor borehole located at the roadway roof, which is $2 \mathrm{~m}$ above the $S_{17}$ borehole, as well as the anchor borehole located at the coal wall, which is $1 \mathrm{~m}$ above the $\mathrm{S}_{17}$ borehole. During the hydraulic fracturing with a constant pumping rate of the $\mathrm{S}_{19}$ borehole, a large amount of water flows out from the $\mathrm{S}_{15}, \mathrm{~S}_{16}, \mathrm{~S}_{17}$, and $\mathrm{S}_{18}$ boreholes. Water also flows out from the anchor borehole located at the roadway roof where is $2 \mathrm{~m}$ above the $\mathrm{S}_{17}$ borehole, as well as the anchor borehole located at the coal wall where is $1 \mathrm{~m}$ above the $S_{17}$ borehole. The coal wall and roof between $S_{17}$ and $S_{18}$ borehole become wet. These phenomena indicate that the hydraulic fractures of the $S_{19}$ borehole have propagated and intersected with the $S_{15}$ borehole, and even extend to the coal seam roof. A large area of the fracture network system is formed in the coal seam.

\section{Control Effect Analysis of Top Coal Hydraulic Fracturing}

\subsection{Analysis of Fragmentation of Top Coal Caving}

The weakening effect of top coal hydraulic fracturing can be reflected by measuring the change in the size and uniformity of top coal caving block, before and after hydraulic fracturing.

\subsubsection{Measuring Tools and Methods}

Measuring tools: Take two PVC pipes with a length of $1.5 \mathrm{~m}$ and a fine rope with a length of $4 \mathrm{~m}$. One end of the fine rope is fixed to one end of the PVC pipe with transparent tape, and the other end is through the other PVC pipe. The fine rope can move freely in the PVC pipe. 
Measuring methods: Use the measuring ends of the two PVC pipes to align with the length or width of the coal block and straighten the fine rope. At this time, the length $(\mathrm{L})$ of the fine rope between the measuring ends of the two PVC pipes represents the length or width of the coal block. The measuring tool is retrieved, and the free end of the fine rope is straightened, then a tape measure is used to measure its length, which equals to the length or width of the coal block (Figure 11).

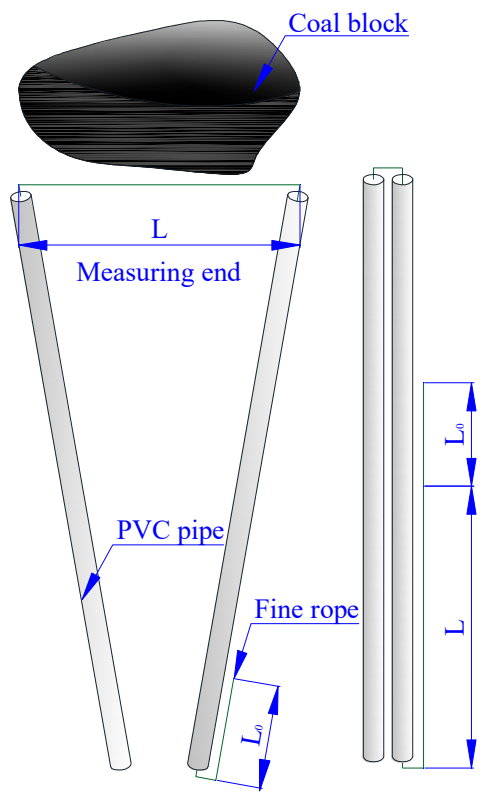

(a)

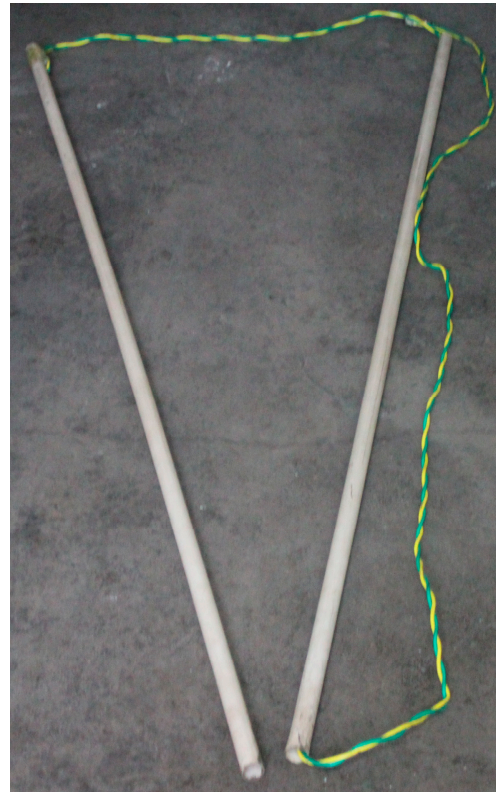

(b)

Figure 11. Method for measuring caving block size of top coal: (a) Measurement principle diagram and (b) Physical map.

\subsubsection{Field Measurements}

Before the hydraulic fracturing construction, the block size of the top coal dropped on the rear scraper conveyor was measured (Figure 12a). One month after the top coal hydraulic fracturing construction, the block size of the top coal dropped on the rear scraper conveyor was measured (Figure 12b). According to the collected data, the contrast curves of top coal caving block size before and after hydraulic fracturing is shown in Figure 13.
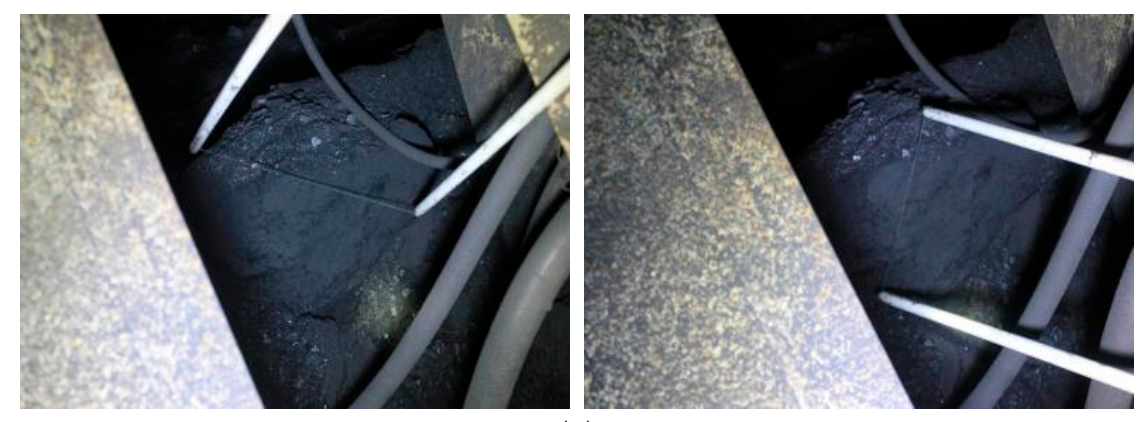

(a)

Figure 12. Cont. 

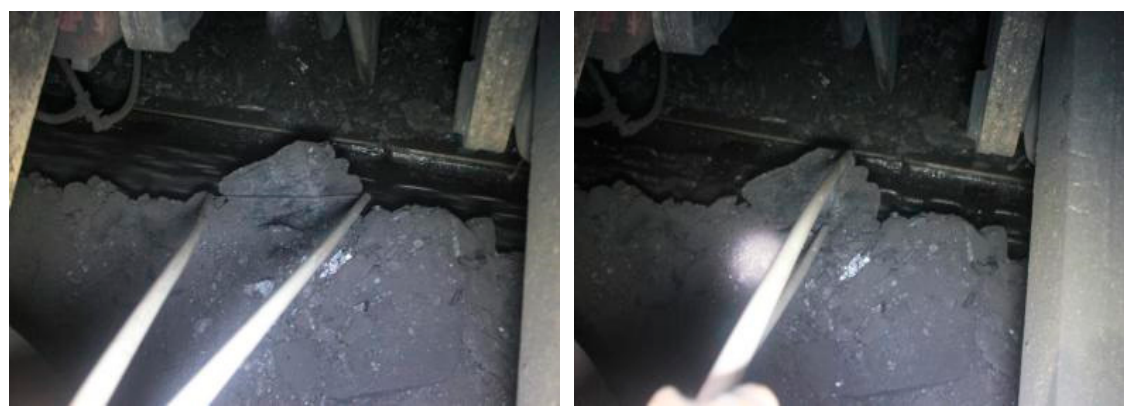

(b)

Figure 12. The caving block size measuring of top coal before and after hydraulic fracturing: (a) before hydraulic fracturing and (b) after hydraulic fracturing.

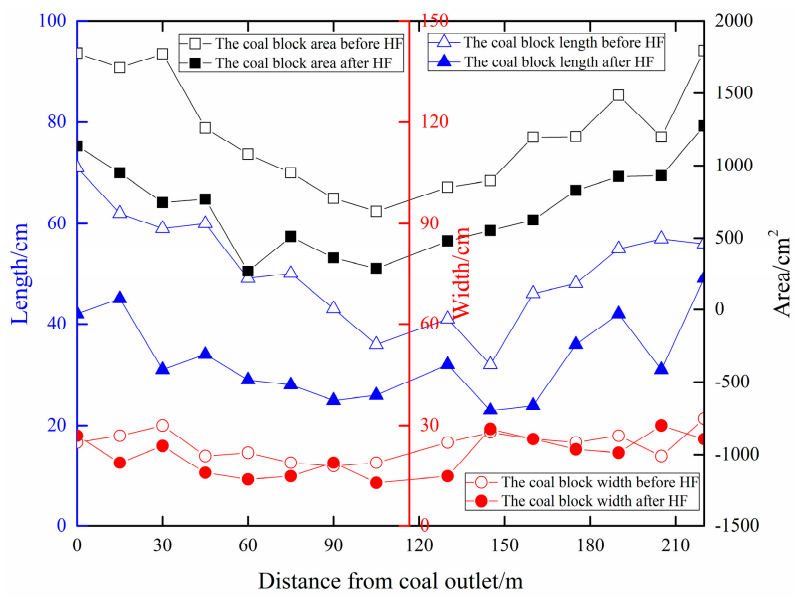

Figure 13. Contrast curves of top coal caving block size before and after hydraulic fracturing.

Before hydraulic fracturing, the average length of the coal caving block is $51 \mathrm{~cm}$, the average width of the coal caving block is $24 \mathrm{~cm}$, the average area is $1239 \mathrm{~cm}^{2}$, and the standard deviation is 368 . After hydraulic cracking, the average length of the coal caving block is $33 \mathrm{~cm}$, the average width of the coal block is $21 \mathrm{~cm}$, the average area of the coal block is $209 \mathrm{~cm}^{2}$, and the standard deviation is 294 . After hydraulic fracturing, the average block size of the top coal caving was reduced by $42 \%$, and the standard deviation was reduced by $20 \%$.

The contrast results of the size and uniformity of top coal caving block before and after hydraulic fracturing illustrated that a dense hydraulic fractures network is generated in the top coal after pre-pulse and constant pumping rate hydraulic fracturing. The dense hydraulic fractures fully cut the coal body, weakening the strength of the top coal, reducing the size of the top coal caving block, and making the top coal caving block more uniform.

\subsection{The Coal Recovery Ratio}

The recovery rate of the working face refers to the percentage of the actual amount of coal extracted in the actual reserves. The actual amount of coal extracted from the working face can be obtained through the statistical production of mine dispatching, and the actual reserves of the working face can be calculated by using Formula (4).

$$
Q=L_{s} \times L_{i} \times h \times \gamma
$$

where $L_{S}$ is the strike length of the working face, $L_{i}$ is the dip length of the working face, $h$ is the thickness of the coal seam, and $\gamma$ is the bulk density of the coal.

The recovery rate of the fully mechanized longwall top coal caving mining face before and after hydraulic fracturing is shown in Figure 14. Before top coal hydraulic fracturing, the top coal caving block is large and is difficult to be recycled from the coal outlet, which resulted in a recovery 
rate of only $67 \%$. After top coal weakening construction by combining pre-pulse and constant pumping rate hydraulic fracturing, the caving block size of the top coal is reduced. The recovery rate reached $81 \%$ during the initial mining stage and then reached $85 \%$ during the normal mining stage. Compared with the recovery rate before hydraulic fracturing, it increased by $18 \%$ after hydraulic fracturing. The weakening technology by combining pre-pulse and constant pumping rate hydraulic fracturing has significantly improved the recovery rate of the fully mechanized longwall top coal caving mining face.

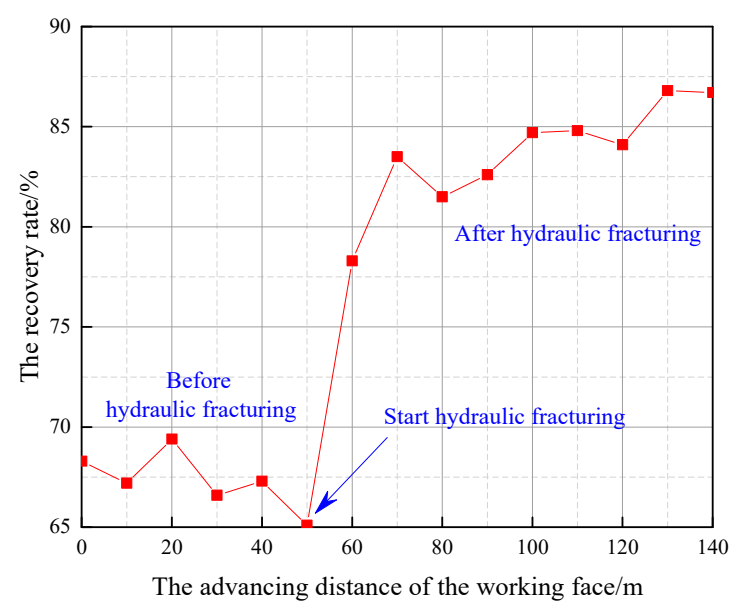

Figure 14. The variation of the coal recovery ratio with working face advancing.

\section{Comparative Analysis of Hydraulic Fracturing Weakening Technology by Combining Pre-Pulse and Constant Pumping Rate to Traditional Blasting Weakening Technology}

\subsection{Technical and Economic Advantages}

\subsubsection{The Complete Improvement of Construction Safety for Top Coal Weakening}

Due to the danger of blasting, the government strictly controls the detonators and explosives, and the blasting pre-splitting underground has a great impact on the safety production of the coal mine. Besides, the safety management of explosive has to be implemented. For high-gas mine, blasting sparks may cause a gas explosion, which is a potential safety hazard. Therefore, poor safety is a prominent problem in traditional hard top coal control technology in the underground coal mine.

The combination of pre-pulse and constant pumping rate hydraulic fracturing uses water as the medium to weaken the top coal, which improves the safety of the hard top coal weakening technology itself, and successfully solves the problem of poor safety of the traditional hard top coal weakening technology in the underground coal mine.

\subsubsection{The Essential Change of Top Coal Crushing Method}

The amount of explosives in a borehole is limited by the diameter and depth of the borehole. A borehole with a fixed hole diameter and depth has a fixed value for the maximum amount of explosive. Based on a large number of theoretical calculations and experimental studies, the radius of the crushed zone produced by the blasting of the mineral water gel explosive is 1.5 to 3 times the borehole radius, and the radius of the fracture zone is 10 to 17 times the borehole radius. Therefore, the total energy for coal breaking in a single hole of explosive blasting is a fixed value, which is called the single borehole constant energy coal breaking method.

The top coal crushing method by hydraulic fracturing is different from explosive blasting. After the borehole is sealed with a packer, high-pressure water continuously inputs to the borehole, and the energy of the high-pressure water is used to break the coal. Therefore, the energy used by hydraulic fracturing to break the top coal continues to increase with time; it has no direct relationship with 
the diameter and the depth of the borehole. The weakening range of a single borehole by hydraulic fracturing is much larger than that of explosive blasting, which can reach 10-100 $\mathrm{m}$. the total energy for coal breaking in a single borehole of hydraulic fracturing is a variable value, which is called the single-hole variable energy coal breaking method.

\subsubsection{Realize Monitoring and Control during Construction}

One of the outstanding problems that restrict the development of hard top coal control technology is that the currently used explosive blasting method has poor controllability in the construction process. To substantially improve the controllability of the construction process, it is necessary to develop supporting measurement and control devices. This study has developed a complete set of equipment for the combined pulse and constant pumping rate hydraulic fracturing construction in the underground coal mine, which includes a pulse hydraulic fracturing measurement and control system. It makes the construction process of top coal weakening controllable, and successfully solves poor controllability problem in the top coal weakening construction process by explosive blasting.

\subsubsection{Significantly Reduced Construction Work}

Another problem is that the traditional explosive blasting method has a large amount of engineering. Because explosive blasting is single-borehole constant energy for coal breaking, the maximum effect radius of a single borehole is 20 times the borehole radius, which is about 1 to $2 \mathrm{~m}$. Hydraulic fracturing is a single-borehole variable-energy for coal breaking, and the effect radius of a single borehole is more than $10 \mathrm{~m}$, which is an order of magnitude higher than that of explosive blasting. The effect range of hydraulic fracturing has nothing to do with the borehole diameter; the most convenient and economical drilling rig can be used for construction. Since the borehole spacing of hydraulic fracturing is greater than that of explosive blasting, the amount of drilling work for hydraulic fracturing is lower.

The hydraulic fracturing construction has two processes: sealing and fracturing. Moreover, explosive blasting construction also has two processes: charging and blasting. The sealing efficiency of hydraulic fracturing is higher, and it is less affected by the drilling depth. Meanwhile, the deep-hole charging is very difficult when the drilling depth is greater than $30 \mathrm{~m}$, and the charging efficiency is very low. Therefore, the hydraulic fracturing has lower engineering and higher efficiency.

\subsubsection{Significantly Reduced Construction Costs}

The cost of hard top coal control mainly includes two aspects: material cost and labor cost. Due to a large amount of engineering, a large number of boreholes are required, the explosive consumption and engineering are large, and the material cost and labor cost are high.

The hydraulic fracturing pump and high-pressure pipeline for hydraulic fracturing are one-time investment and can be used for a long time. The sealing device and high-pressure sealing installation pipe are materials that can be reused for a certain number of times, which greatly reduces the amount of construction consumables. Meanwhile, due to the large effect range of the single borehole of hydraulic fracturing, the number of boreholes required to weaken hard top coal is less, the amount of construction works is small, and the labor cost is low. Therefore, the hydraulic fracturing technology greatly reduces the construction cost of hard top coal control.

\subsubsection{Significantly Improved Production Efficiency}

It is necessary to carry out three inspections for one shot, and the personnel must be evacuated during the blasting operation for weakening top coal. Therefore, the working face needs to stop production intermittently, the production efficiency of the working face is reduced. Meanwhile, the weakening technology by combining pre-pulse and constant pumping rate hydraulic fracturing can work in coordination with production. It does not affect the normal production of the working face, thereby improving the production efficiency of the working face. 


\subsubsection{Wide Range of Applications}

Blasting weakening is not suitable for fully mechanized top coal caving mining in high-gas coal seam because of its potential safety hazard. The weakening technology by combining pre-pulse and constant pumping rate hydraulic fracturing is suitable for low- and high-gas coal seams.

\subsection{Case Study}

During the initial mining period of 4307 fully mechanized caving face in Bailu Coal Mine, explosive blasting was used to weaken the top coal and improve the caving property of top coal. The layout of the blasting boreholes is shown in Figure 15. Boreholes are drilled vertically at a distance of $2.5 \mathrm{~m}$ from the coal wall. The diameter of the boreholes is $32 \mathrm{~mm}$, the length of the boreholes is $3 \mathrm{~m}$, and the spacing of the boreholes is $7.5 \mathrm{~m}$. For every $0.8 \mathrm{~m}$ advancing of the working face, a row of blast boreholes is drilled, and then one blasting pre-splitting is carried out.

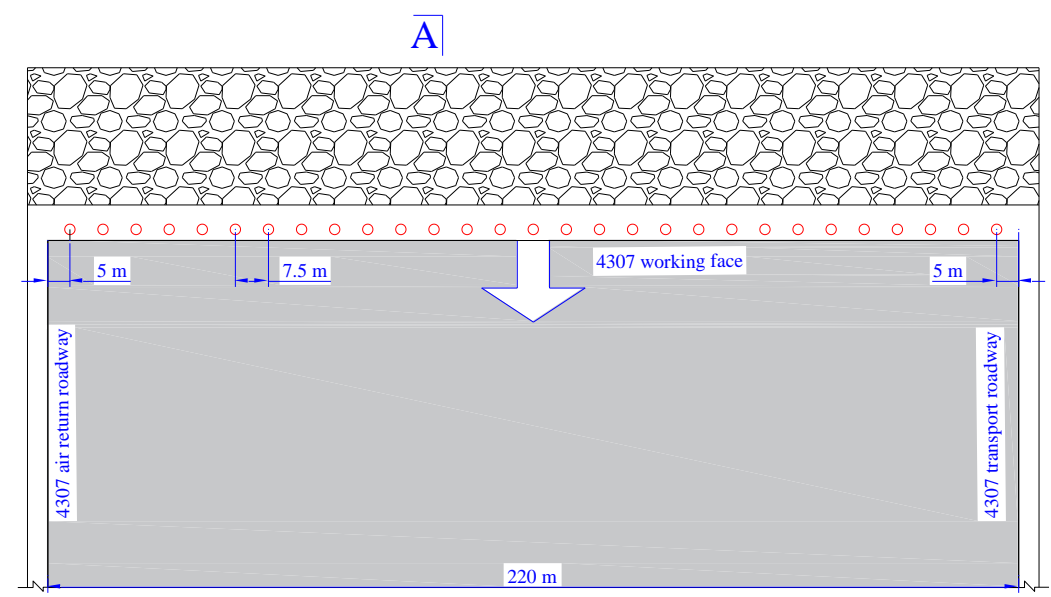

A

(a)

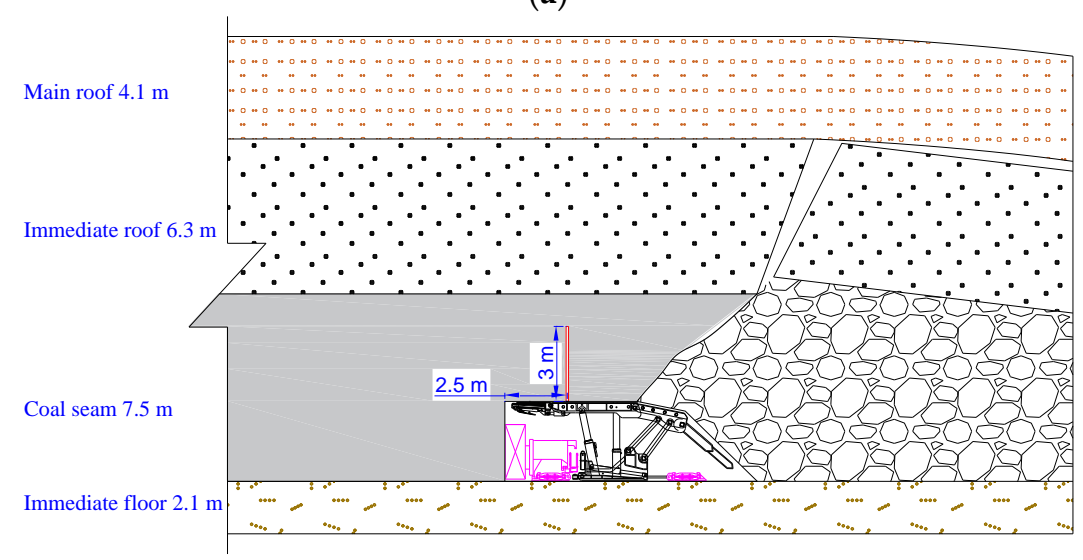

(b)

Figure 15. Blasting borehole layout of 4307 fully mechanized caving face in Bailu Coal Mine: (a) plan view and (b) A-A sectional view.

\subsubsection{Construction Quantity}

According to the calculation of the technical scheme, the drilling construction quantity of blasting pre-splitting borehole is $470 \mathrm{~m}$ per ten thousand tons. The drilling construction quantity of hydraulic fracturing borehole is $88 \mathrm{~m}$ per ten thousand tons. 
It can be seen that the construction quantity of hydraulic fracturing combined pre-pulse and constant pumping rate is less than that of blasting pre-splitting, which is caused by the large effect range of single borehole hydraulic fracturing weakening.

\subsubsection{Cost-Effectiveness}

(1) Labor costs

Because the blasting pre-splitting borehole needs to be constructed between hydraulic support, it can only be drilling by a small drilling rig. Besides, due to the small spacing and a large number of boreholes, the drilling rig has to be moved many times, so, each miner can complete $42 \mathrm{~m}$ in one shift. While the big drilling rig is used for the construction of the hydraulic fracturing borehole with a diameter of $\Phi 75 \mathrm{~mm}$ in the roadway, the drilling rig does not need to move frequently, and each miner can complete $50 \mathrm{~m}$ in one shift.

It can be calculated that the labor costs of traditional blasting pre-splitting are 11.2 labor per ten thousand tons, and the labor costs of the weakening technology by combining pre-pulse and constant pumping rate hydraulic fracturing is 1.7 labor per ten thousand tons.

Therefore, the labor costs of the weakening technology by combining pre-pulse and constant pumping rate hydraulic fracturing are about $1 / 7$ of the labor costs of traditional blasting pre-splitting.

(2) Material consumption

In total, $2.25 \mathrm{~kg}$ explosive and one detonator were consumed for each blasting pre-splitting borehole. The total material consumption of blasting pre-splitting is shown in Table 2.

Table 2. Materials consumption of blasting.

\begin{tabular}{ccc}
\hline Material Consumption & Explosive Quantity (kg) & Detonator Quantity (No.) \\
\hline Every 0.8 m advancing of working face & 67.5 & 30 \\
\hline
\end{tabular}

The unit price of explosives is $1.73 \mathrm{USD} / \mathrm{Kg}$, and the unit price of the detonator is $0.4 \mathrm{USD}$. The material consumption cost during normal advancing of the working face is as follows.

$$
\frac{\text { Explosive consumption }}{\text { Resources of the working face advancing } 0.8 \mathrm{~m}}=672.48 \mathrm{USD} / \text { ten thousand tons }
$$

Therefore, the material cost of blasting pre-splitting weakening is $672.48 \mathrm{USD} /$ per ten thousand tons.

The hydraulic fracturing pump and high-pressure pipeline for hydraulic fracturing are a one-time investment and can be used for a long time. The sealing device and high-pressure sealing installation pipe are materials that can be reused for a certain number of times. The total material consumption of hydraulic fracturing is shown in Table 3.

$$
\frac{\text { Materials consumption }}{\text { Resources of the working face advancing } 200 \mathrm{~m}}=227.23 \text { USD/ten thousand tons }
$$

Table 3. Materials consumption of hydraulic fracturing combining pre-pulse and constant pumping rate.

\begin{tabular}{ccc}
\hline Material Consumption & High-Pressure Sealing Installation Pipe (No.) & Sealing Device (No.) \\
\hline Every 200 m advancing of working face & 210 & 10 \\
\hline
\end{tabular}

Therefore, the material cost of the weakening technology by combining pre-pulse and constant pumping rate hydraulic fracturing is $227.23 \mathrm{USD} /$ per ten thousand tons.

The material cost of the weakening technology by combining pre-pulse and constant pumping rate hydraulic fracturing is about $1 / 3$ of that of blasting weakening technology. 


\subsubsection{Recovery Rate}

The basic requirement of fully mechanized top coal caving mining is that the top coal should fall timely and fully from the back of hydraulic support. The caving block size of top coal should meet the requirements of the coal caving port, as well as the coal passing height of the scraper conveyor at the rear of the hydraulic support. Blasting weakening is to directly crush the top coal to the loose block, which can meet the requirements of coal caving. Hydraulic fracturing weakening is to form a fracture network in coal-and-rock mass in advance, and then the top coal is further broken into loose blocks under the action of mine pressure. The effect and law of coal breaking by mine pressure have not changed substantially.

The theory and practice show that the top coal recovery rate of the weakening technology by combining pre-pulse and constant pumping rate hydraulic fracturing is basically the same as that of blasting weakening.

In conclusion, the weakening technology by combining pre-pulse and constant pumping rate hydraulic fracturing can replace the traditional explosive blasting weakening technology. Under the condition of meeting the top coal recovery rate, the safety of the top coal weakening is improved, as well as the production efficiency of the working face. Meanwhile, the construction quantity and cost of the top coal weakening are reduced, and the scope of application is wide.

\section{Conclusions}

(1) Based on the characteristics of pulse hydraulic fracturing and constant pumping rate hydraulic fracturing, a weakening method for hard coal-and-rock mass by combining pre-pulse and constant pumping rate hydraulic fracturing is proposed.

(2) The technology process of combining pulse and constant pumping rate hydraulic fracturing is formed. A complete set of equipment for the combined pulse and constant pumping rate hydraulic fracturing construction in the underground coal mine is developed, which can meet construction requirements.

(3) The water pressure is between 2 and $7 \mathrm{MPa}$ during pulse hydraulic fracturing and is between 8 and $20 \mathrm{MPa}$ during constant pumping rate hydraulic fracturing in the coal seam of Bailu Coal Mine.

(4) The fractures propagation range during pulse hydraulic fracturing in the coal seam is at least $10 \mathrm{~m}$, and it can be up to $40 \mathrm{~m}$ after the following hydraulic fracturing with a constant pumping rate.

(5) The complete set of pulse and constant pumping rate hydraulic fracturing technology and equipment were applied in the top coal weakening of the shallow buried thick coal seam. Without the use of explosives, it successfully guaranteed the normal and safe production of fully mechanized longwall top coal caving face. Compared with no weakening measures for top coal, the average block size of the top coal caving reduced by $42 \%$, and the recovery rate increased by $18 \%$ after hydraulic fracturing.

(6) The technology that combined the pulse and constant pumping rate hydraulic fracturing can be applied to the control of hard roofs in coal mines, the top coal weakening, and the control of hanging roof in the gob of non-coal mine.

Author Contributions: Conceptualization, B.H.; data curation, L.S., S.C., H.L. and C.W.; methodology, Q.C., L.S., S.C. and X.Z.; writing-original draft preparation, Q.C.; writing-review and editing, B.H. and X.Z.; supervision, B.H.; project administration, B.H. All authors have read and agreed to the published version of the manuscript.

Funding: The National Key Research and Development Program of China (No. 2016YFC0802900), and the National Natural Science Foundation of China (No. 51704285).

Acknowledgments: Financial support for this work, provided by the National Key Research and Development Program of China (No. 2016YFC0802900) and the National Natural Science Foundation of China (No. 51704285), is gratefully acknowledged.

Conflicts of Interest: The authors declare no conflict of interest. 


\section{References}

1. Bai, Q.S.; Tu, S.H.; Wang, F.T.; Zhang, C. Field and numerical investigations of gateroad system failure induced by hard roofs in a longwall top coal caving face. Int. J. Coal Geol. 2017, 173, 176-199. [CrossRef]

2. Cui, F.; Dong, S.; Lai, X.P. Study on Rule of Overburden Failure and Rock Burst Hazard under Repeated Mining in Fully Mechanized Top-Coal Caving Face with Hard Roof. Energies 2019, 12, 4780. [CrossRef]

3. Banerjee, G.; Ray, A.K.; Singh, G.S.P. Hard roof management-a key for high productivity in longwall coal mines. J. Mines Metals Fuels 2003, 51, 238-244.

4. Sawmliana, C.; Pal, R.P. Management in blasting gallery method. Geol. Eng. 2012, 30, 1357-1367.

5. Huang, R.; Shen, X.; Wang, B.; Liao, X.P. Migration characteristics of CO under forced ventilation after excavation roadway blasting: A case study in a plateau mine. J. Clean. Prod. 2020, 267, 122094. [CrossRef]

6. Yardimci, A.G.; Karakus, M. A new protective destressing technique in underground hard coal mining. Int. J. Rock Mech. Min. Sci. 2020, 130, 104327. [CrossRef]

7. Junnhyeok, P.; Kwangmin, K. Estimation of fines generation in blasting using dynamic rock properties and a near-field PPV damage model. Min. Metall. Explor. 2020, 37, 1169-1183.

8. Huang, B.X.; Zhao, X.L.; Chen, S.L. Theory and technology of controlling hard roof with hydraulic fracturing in underground mining. Chin. J. Rock Mech. Eng. 2017, 36, 2952-2970.

9. Jeffrey, R.; Mill, K. Hydraulic fracturing applied to inducing longwall coal mine goaf falls. Pac. Rocks 2000, 20, 423-430.

10. Shimada, H.; Matsui, K.; Anwar, H. Control of hard-to-collapse massive roofs in longwall faces using a hydraulic fracturing technique. In Proceedings of the 17th International Conference on Ground Control in Mining, Morgantown, WV, USA, 4-6 August 1998; pp. 79-87.

11. Hubbert, M.K.; Willis, D.G. Mechanics of hydraulic fracturing. Trans. AIME 1957, 210, 153-166. [CrossRef]

12. Li, Q.G.; Lin, B.Q.; Zhai, C. A new technique for preventing and controlling coal and gas outburst hazard with pulse hydraulic fracturing: A case study in Yuwu coal mine, China. Nat. Hazards 2015, 75, 2931-2946. [CrossRef]

13. Li, Q.G.; Lin, B.Q.; Zhai, C.; Ni, G.H.; Peng, S.; Sun, C.; Cheng, Y.Y. Variable frequency of pulse hydraulic fracturing for improving permeability in coal seam. Int. J. Min. Sci. Tech. 2013, 23, 847-853. [CrossRef]

14. Lin, B.Q.; Li, Z.W.; Zhai, C.; Bi, Q. Pressure relief and permeability_Increasing technology based on high pressure pulsating hydraulic fracturing. J. Min. Safety Eng. 2011, 28, 452-455.

15. Xu, J.; Zhai, C.; Qin, L. Mechanism and application of pulse hydraulic fracturing in improving drainage of coalbed methane. J. Nat. Gas Sci. Eng. 2017, 40, 79-90. [CrossRef]

16. Ramos, J.; Wang, W.L.; Diessl, J. Advanced hydraulic fracture characterization using pulse testing analysis. Rock. Mech. Rock. Eng. 2019, 52, 5047-5069. [CrossRef]

17. Stephansson, O.; Semikova, H.; Zimmermann, G. Laboratory pulse test of hydraulic fracturing on granitic sample cores from Aspo HRL, Sweden. Rock Mech. Rock Eng. 2019, 52, 629-633. [CrossRef]

18. Huang, B.X.; Cheng, Q.Y.; Zhao, X.L. Using hydraulic fracturing to control caving of the hanging roof during the initial mining stages in a longwall coal mine: A case study. Arab. J. Geosci. 2018, 11, 603. [CrossRef]

19. Xie, J.N.; Xie, J.; Ni, G.H.; Sheik, R.; Sun, Q.; Wang, H. Effects of pulse wave on the variation of coal pore structure in pulsating hydraulic fracturing process of coal seam. Fuel 2020, 264, 116906.

20. Li, Q.G.; Lin, B.Q.; Zhai, C. The effect of pulse frequency on the fracture extension during hydraulic fracturing. J. Nat. Gas. Sci. Eng. 2014, 21, 296-303. [CrossRef]

21. Ma, C.C.; Jiang, Y.P.; Xing, H.L.; Li, T.B. Numerical modelling of fracturing effect stimulated by pulsating hydraulic fracturing in coal seam gas reservoir. J. Nat. Gas Sci. Eng. 2017, 46, 651-663. [CrossRef]

22. Ni, G.H.; Dong, K.; Li, S.; Sun, Q. Gas desorption characteristics effected by the pulsating hydraulic fracturing in coal. Fuel 2019, 236, 190-200.

23. Peng, K.; Zhou, J.; Zou, Q.L.; Sun, X. Effect of loading frequency on the deformation behaviours of sandstones subjected to cyclic loads and its underlying mechanism. Int. J. Fatigue 2020, 131, 105349. [CrossRef]

24. Xu, J.; Zhai, C.; Qin, L.; Liu, S.M. Pulse hydraulic fracturing technology and its application in coalbed methane extraction. Int. J. Oil Gas Coal Tech. 2018, 19, 115-133. [CrossRef]

25. Xia, B.W.; Zhang, X.; Yu, B. Weakening effects of hydraulic fracture in hard roof under the influence of stress arch. Int. J. Mining Sci. Technol. 2018, 28, 951-958. [CrossRef] 
26. Huang, B.X.; Liu, J.W.; Zhang, Q. The reasonable breaking location of overhanging hard roof for directional hydraulic fracturing to control strong strata behaviors of gob-side entry. Int. J. Rock Mech. Mining Sci. 2018, 103, 1-13. [CrossRef]

27. Liu, T.; Lin, B.Q.; Xiao, W. A safe mining approach for deep outburst coal seam groups with hard-thick sandstone roof: Stepwise risk control based on gas diversion and extraction. Energy Sci. Eng. 2020. [CrossRef]

28. Huang, B.X.; Huang, C.M.; Cheng, Q.Y.; Huang, C.H.; Xue, W.C. Hydraulic fracturing technology for improving permeability in gas-bearing coal seams in underground coal mines. J. S. Afr. Inst. Min. Metall. 2012, 112, 485-495.

29. Hu, Q.T.; Liu, L.; Li, Q.Q. Experimental investigation on crack competitive extension during hydraulic fracturing in coal measures strata. Fuel 2020, 265, 117003. [CrossRef]

30. Lu, Y.Y.; Wang, L.; Ge, Z.L. Fracture and pore structure dynamic evolution of coals during hydraulic fracturing. Fuel 2020, 259, 116272. [CrossRef]

31. Lu, A.H. The Dynamic Mechanism of Rock Burst Induced by Stress Wave; China University of Mining and Technology Press: Xuzhou, China, 2005.

32. Li, X.Z. Mechanism and Technology of High-Pressure Pulsating Hydraulic Fracturing; China University of Mining and Technology: Xuzhou, China, 2013.

33. Xie, H.P.; Ju, Y.; Dong, L.L. Discussion of elastic modulus method defined in classic damage. Mech. Eng. 1997, 19, 1-5.

Publisher's Note: MDPI stays neutral with regard to jurisdictional claims in published maps and institutional affiliations.

(C) 2020 by the authors. Licensee MDPI, Basel, Switzerland. This article is an open access article distributed under the terms and conditions of the Creative Commons Attribution (CC BY) license (http://creativecommons.org/licenses/by/4.0/). 